\title{
Amiodarone pulmonary toxicity
}

\author{
Norman Wolkove MD FRCP, Marc Baltzan MD FRCP
}

N Wolkove, M Baltzan. Amiodarone pulmonary toxicity. Can Respir J 2009;16(2):43-48.

Amiodarone is an antiarrhythmic agent commonly used to treat supraventricular and ventricular arrhythmias. This drug is an iodinecontaining compound that tends to accumulate in several organs, including the lungs. It has been associated with a variety of adverse events. Of these events, the most serious is amiodarone pulmonary toxicity. Although the incidence of this complication has decreased with the use of lower doses of amiodarone, it can occur with any dose. Because amiodarone is widely used, all clinicians should be vigilant of this possibility. Pulmonary toxicity usually manifests as an acute or subacute pneumonitis, typically with diffuse infiltrates on chest $\mathrm{x}$-ray and high-resolution computed tomography. Other, more localized, forms of pulmonary toxicity may occur, including pleural disease, migratory infiltrates, and single or multiple nodules. With early detection, the prognosis is good. Most patients diagnosed promptly respond well to the withdrawal of amiodarone and the administration of corticosteroids, which are usually given for four to 12 months. It is important that physicians be familiar with amiodarone treatment guidelines and follow published recommendations for the monitoring of pulmonary as well as extrapulmonary adverse effects.

\section{Toxicité pulmonaire de l'amiodarone}

L'amiodarone est un antiarythmique couramment utilisé pour traiter les arythmies supraventriculaires et ventriculaires. Ce médicament renferme de l'iode qui a tendance à s'accumuler dans plusieurs organes, notamment dans les poumons. Il a été associé à divers effets indésirables, dont le plus grave est la toxicité pulmonaire induite par l'amiodarone. Bien que l'incidence de cette complication ait diminué grâce à la réduction des doses d'amiodarone employées, elle peut survenir à n'importe quelle dose. Étant donné que l'amiodarone est couramment utilisée, tous les médecins doivent rester à l'affût de cette complication possible. La toxicité pulmonaire se manifeste habituellement sous la forme d'une pneumonie aiguë ou subaiguë, généralement accompagnée d'infiltrats diffus à la radiographie pulmonaire et à la tomodensitométrie haute résolution. D'autres formes plus localisées de toxicité pulmonaire s'observent aussi parfois, notamment une atteinte pleurale, des infiltrats migratoires et des nodules simples ou multiples. Un dépistage précoce améliore le pronostic et la plupart des patients chez qui le diagnostic est posé sans retard répondent bien à l'arrêt de l'amiodarone et à l'administration de corticostéroïdes, habituellement pendant quatre à 12 mois. Il est important que les médecins soient renseignés sur les directives thérapeutiques relatives à l'amiodarone et suivent les recommandations publiées pour la surveillance des effets secondaires pulmonaires et autres.

Key Words: Amiodarone; Amiodarone lung toxicity; Drug toxicity

$\Delta$ miodarone is one of the most commonly prescribed Aantiarrhythmic medications in North America (1). In Canada, for the year 2007, approximately 500,000 prescriptions for this drug were dispensed by retail pharmacies (IMS Health Canada, Canadian CompuScript; personal communication). Prescriptions for this medication have increased over the past three years, while those for sotalol, by comparison, have decreased slightly. The increased use of amiodarone has also been noted in other countries. In Australia, for example, its use increased approximately fourfold from 1994 to 2003 (2). The popularity of amiodarone may be explained by its efficacy and usefulness in reducing or preventing common arrhythmias. However, amiodarone has been found to be associated with a variety of adverse effects. The most serious of these is amiodarone pulmonary toxicity (APT). In the present review, we first summarize the clinical use and unique pharmacology of amiodarone, and then discuss the incidence, features and treatment of APT. Finally, current recommendations for monitoring patients requiring amiodarone are presented.

\section{CLINICAL USE OF AMIODARONE}

Originally developed as an antianginal agent because of its vasodilatory properties, amiodarone was also found to suppress tachyarrhythmias. It has multiple well-described biochemical and electrophysiological effects $(1,3,4)$. Clinically, amiodarone has been used in the treatment of ventricular arrhythmias such as recurrent ventricular tachycardia and ventricular fibrillation $(1,5)$. In the acute situation, it can be administered intravenously when rapid onset of action is imperative. It is also useful for atrial arrhythmias. Amiodarone slows the ventricular response to atrial flutter and atrial fibrillation at rest and during exercise. It can maintain sinus rhythm in patients with paroxysmal atrial fibrillation and in some patients convert atrial fibrillation to sinus rhythm $(1,3,4)$. In the Canadian Trial of Atrial Fibrillation (CTAF), amiodarone was more effective than propafenone or sotalol in preventing atrial fibrillation recurrences, although discontinuation rates due to adverse effects were higher (6). Amiodarone has also been used prophylactically in the perioperative period in patients undergoing thoracic surgery, including valve replacement and coronary revascularization (7).

\section{CLINICAL PHARMACOLOGY}

Amiodarone is an iodine-containing compound with some structural similarities to thyroxine (1). Because of its iodine content, amiodarone can cause either hypo- or hyperthyroidism 


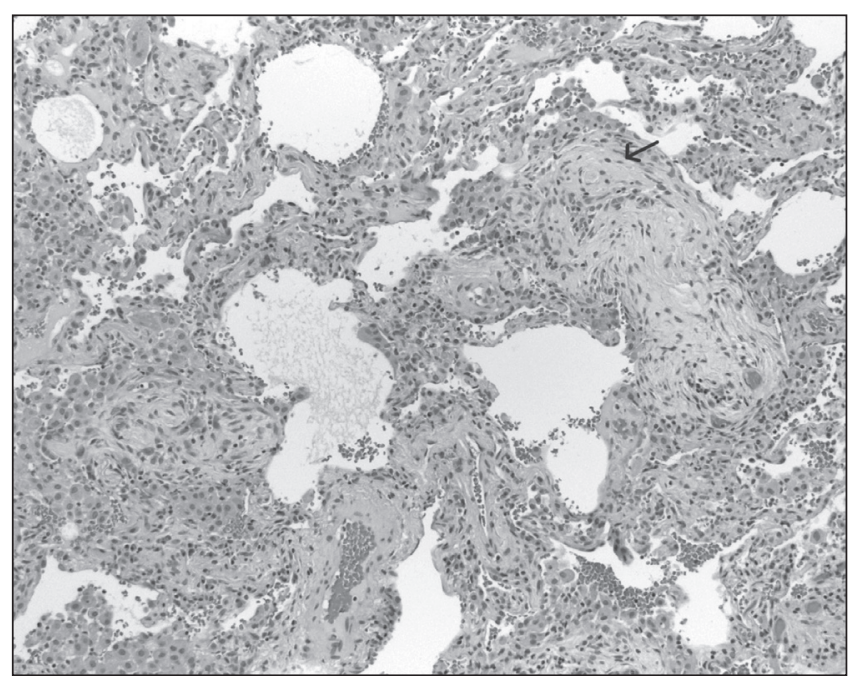

Figure 1) Lung parenchyma showing interstitial inflammation and thickening with fibroblastic tissue in airway lumens consistent with organizing pneumonia (arrow) (hematoxylin and eosin stain, original magnification $\times 100)$

in some patients. In addition, inhibition of thyroxine deiodination to triiodothyroxine may contribute to its antiarrhythmic efficacy (1).

When taken orally, amiodarone is absorbed slowly and incompletely, although its bioavailability may be enhanced if it is taken with food. An important property of amiodarone is its high lipid solubility. It tends to accumulate extensively in adipose tissue and highly perfused organs such as the liver, lungs and spleen $(1,4,5)$. The large volume of distribution results in a delayed onset of action when taken orally (two to three days) and a long elimination half-life (up to six months) (1). Amiodarone is metabolized to desethylamiodarone (DEA) by the cytochrome P450 enzyme system chiefly in the liver (1). Following hepatic metabolism, it is excreted via the biliary system and only very small amounts of amiodarone and DEA are found in the urine. When considering therapeutic options in cases of amiodarone toxicity, one should bear in mind that neither the drug itself nor its chief metabolite DEA are removed by dialysis (3).

\section{EPIDEMIOLOGY: INCIDENCE OF TOXICITY}

The risk of toxicity from this drug increases with higher plasma concentrations of amiodarone (8). However, APT correlates better with the total cumulative dose rather than with the daily dose or plasma concentration of amiodarone $(8,9)$. Although toxicity can occur at any time after treatment is initiated, those considered at greatest risk are individuals who have received a daily dose of $400 \mathrm{mg}$ or more for more than two months, or a lower dose, commonly $200 \mathrm{mg}$ daily, for more than two years $(9,10)$.

In the earliest descriptions of APT when patients were usually taking $400 \mathrm{mg}$ or more per day, the reported incidence of APT was $5 \%$ to $15 \%(9-12)$. Subsequently, lower doses were used in an attempt to avoid toxicity. A lower rate of APT $(1.6 \%)$ was recorded from combined trials in patients receiving daily amiodarone doses of $400 \mathrm{mg}$ or less (13). This is consistent with the estimated rate of $2 \%$ reported by Goldschlager et al (14) in 2007. As Polkey et al (15) emphasized, there is probably no 'safe' dose of this medication, and this complication continues to be reported. Thus, even at $200 \mathrm{mg} /$ day, the dose most commonly used by cardiologists, Ott et al (16) reported eight cases of APT. These authors reinforced the need for vigilance even with 'low-dose' amiodarone therapy.

APT is more frequent in men and increases with age (10). Individuals with pre-existing lung disease appear to be more susceptible $(9,10)$. Interestingly, there may be ethnic or racial differences in the susceptibility to APT. Thus, in a Japanese population, Yamada et al (17) found a relatively high cumulative incidence of $4.2 \%, 7.8 \%$ and $10.6 \%$ at one, three and five years, respectively, even though the mean maintenance dose was only $141 \mathrm{mg}$ daily.

There is evidence that exposure to supplemental $\mathrm{O}_{2}$, especially in high concentrations, alone or when combined with mechanical ventilation, may potentiate APT $(10,18,19)$. Therefore, patients who undergo thoracic surgery and are receiving amiodarone are particularly vulnerable because they may require these supportive modalities in the postoperative period when their ventilatory reserve is compromised $(16,19,20)$.

\section{PATHOLOGY}

Amiodarone and its metabolites can produce lung damage directly by a cytotoxic effect and indirectly by an immunological reaction $(9,12)$. The latter is supported by the finding of cytotoxic $\mathrm{T}$ cells in bronchoalveolar lavage (BAL) fluid from patients with diagnosed APT $(9,11,12)$. Amiodarone may induce the production of toxic $\mathrm{O}_{2}$ radicals, which can directly damage cells (9). It also appears to promote the accumulation of phospholipids in tissues (9). Typically, the lungs of patients with APT show a diffuse interstitial pneumonitis on microscopic inspection (Figure 1). There is hyperplasia of type II pneumocytes and widening of alveolar septae with a cellular inflammatory infiltrate and varying degrees of interstitial fibrosis. On light microscopy, vacuolization of the cytoplasm is seen in alveolar pneumocytes, bronchial epithelial cells and endothelial cells $(21,22)$ (Figure 2). A characteristic finding is accumulation of lipid-laden 'foamy' macrophages in alveolar spaces. Ultrastructural examination of these cells shows membrane-bound lamellar bodies. These lipid particles are similar to surfactant (22). It should be noted, however, that foamy macrophages sometimes with lamellated inclusion bodies have been reported in nontoxic patients receiving chronic amiodarone therapy (23). Thus, Myers et al (24) concluded that while foamy alveolar macrophages and cytoplasmic lamellar bodies are characteristic of APT, they are not specific for this condition and their presence alone does not distinguish toxic patients from those merely exposed to the drug.

In some cases, there is little evidence of an inflammatory process and the predominant finding is nonspecific pulmonary fibrosis. This may be found after an episode of typical APT or be diagnosed in a patient on amiodarone when symptoms become apparent in the absence of an acute antecedent event $(10,25)$.

Less frequent pathological manifestations of APT include patchy bronchiolitis obliterans organizing pneumonia or in severe cases, diffuse alveolar damage with hyaline membrane formation (10). Amiodarone-induced alveolar hemorrhage has also been reported but appears to be rare (26). 


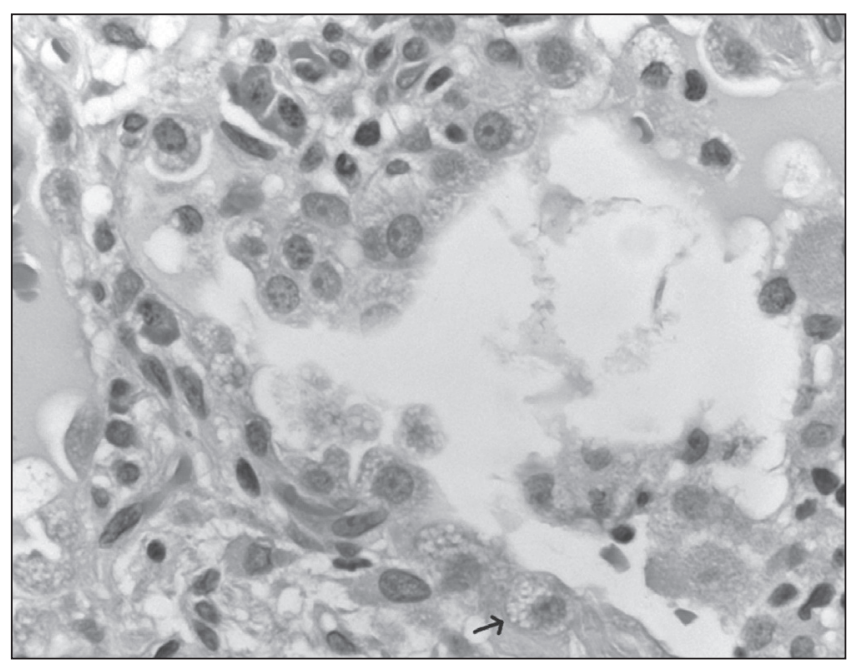

Figure 2) Microscopic image of an alveolus showing interstitial inflammation and type II pneumocyte hyperplasia. The pneumocytes show many coarse cytoplasmic vacuoles (arrow) (hematoxylin and eosin stain, original magnification $\times 400$ )

\section{CLINICAL FINDINGS}

Several clinical presentations have been described in patients with APT. The most common presentation is that of an alveolar/ interstitial pneumonitis with a subacute onset. Typically, patients have been on amiodarone for months or even several years. Individuals usually present with progressive shortness of breath, nonproductive cough, malaise, fever and occasionally pleuritic chest pain $(10,11,16)$. Physical examination may be unremarkable in milder cases, but in more severely affected individuals, diffuse rales, hypoxemia and respiratory distress may be noted.

\section{Laboratory features}

Laboratory data may reveal a leukocytosis that is rarely due to eosinophilia (10). A nonspecific elevation in lactic dehydrogenase or serum KL-6, a mucin-like glycoprotein, is often present but does not distinguish APT from other interstitial lung diseases $(10,27)$.

\section{Pulmonary function testing}

Pulmonary function testing usually reveals low lung volumes and a restrictive pattern. A reduced diffusing capacity of the lung for carbon monoxide $\left(\mathrm{DL}_{\mathrm{CO}}\right)$ is typical but nonspecific. Varying degrees of hypoxemia are seen, as measured by simple pulse oximetry or by arterial blood gas determination.

\section{Radiographic features}

Radiology plays a central role in diagnosis. Chest $\mathrm{x}$-rays reveal patchy or diffuse infiltrates, which are commonly bilateral (Figure 3). Some infiltrates have a 'ground glass' appearance. It has been noted that the right lung, especially the right upper lobe, is more frequently involved than the left lung $(10,21,22)$. High-resolution computed tomography (HRCT) scanning often reveals more extensive disease than noted on the chest $\mathrm{x}$-ray. Such imaging usually reveals bilateral interstitial, alveolar or mixed interstitial and alveolar infiltrates (28) (Figure 4). Parenchymal infiltrates that have high attenuation are typical and believed to be associated with the iodinated properties of the drug and its prolonged half-life in the lung.

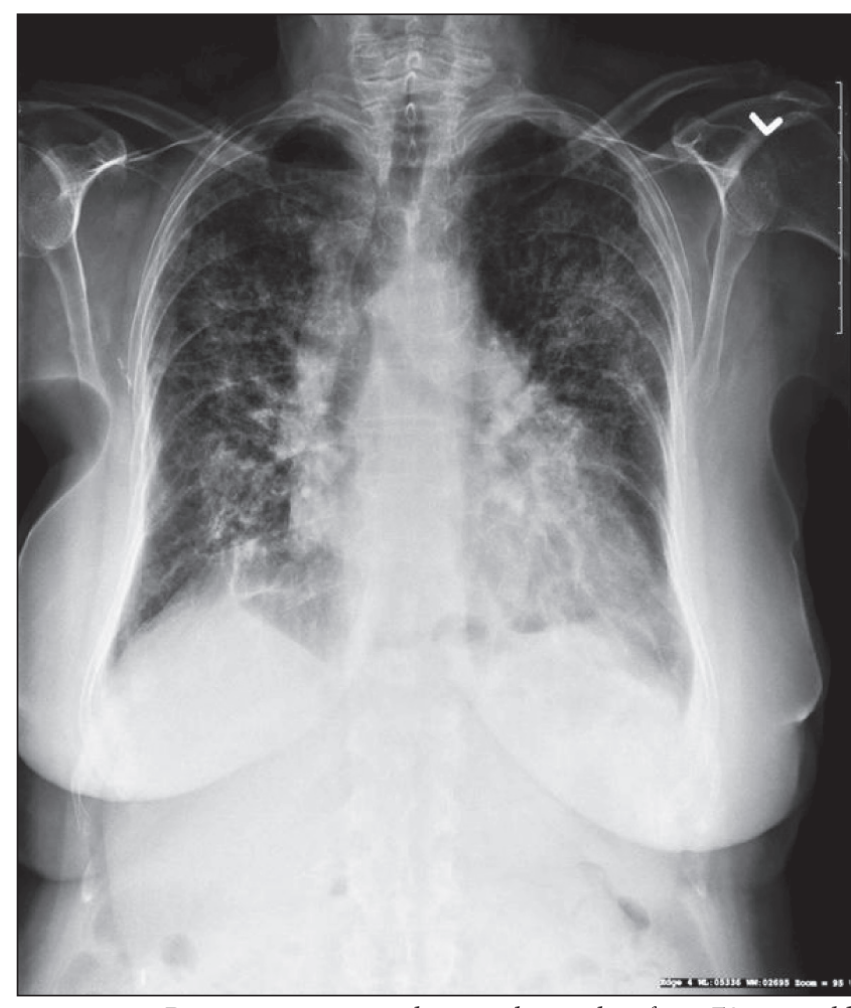

Figure 3) Posterior-anterior chest radiograph of a 79-year-old woman with amiodarone pulmonary toxicity. Bilateral patchy airspace and interstial infiltrates are seen

Ground glass opacities are appreciated more easily and seen more frequently on HRCT scanning than on chest $\mathrm{x}$-ray imaging (29). They are often distributed in a peripheral manner and may be an early finding in APT. Oyama et al (29) speculated that the initial findings of APT are ground glass opacities, and that these are a clue for detection of this complication at an early, potentially reversible stage. Pleural thickening is commonly seen, especially in areas where the infiltrates are densest. Pleural effusions have been described but are less common (10).

High attenuation may be noted incidentally during HRCT on views of the liver and spleen, related to the accumulation of amiodarone and its metabolites in tissue macrophages. This latter finding, although suggestive of amiodarone exposure, is not necessarily associated with APT. The HRCT findings in APT are summarized in Table 1.

Gallium scanning may demonstrate increased parenchymal activity in some cases, particularly in those with early or mild disease. Gallium image abnormalities can parallel the development of APT and may help differentiate it from infiltrates due to congestive heart failure, a condition not infrequently seen in this population (30). However, the findings on gallium scanning are not specific; the test is relatively costly and requires an interval of $48 \mathrm{~h}$ to $72 \mathrm{~h}$ between gallium administration and test performance.

In some cases with typical symptoms and signs, patchy infiltrates (frequently migratory) are found on chest $\mathrm{x}$-ray. On further investigation, an open lung biopsy reveals bronchiolitis obliterans with organizing pneumonia $(10,16)$. Frequently, this is seen as a minor component in an otherwise typical picture of diffuse interstitial pneumonitis. 

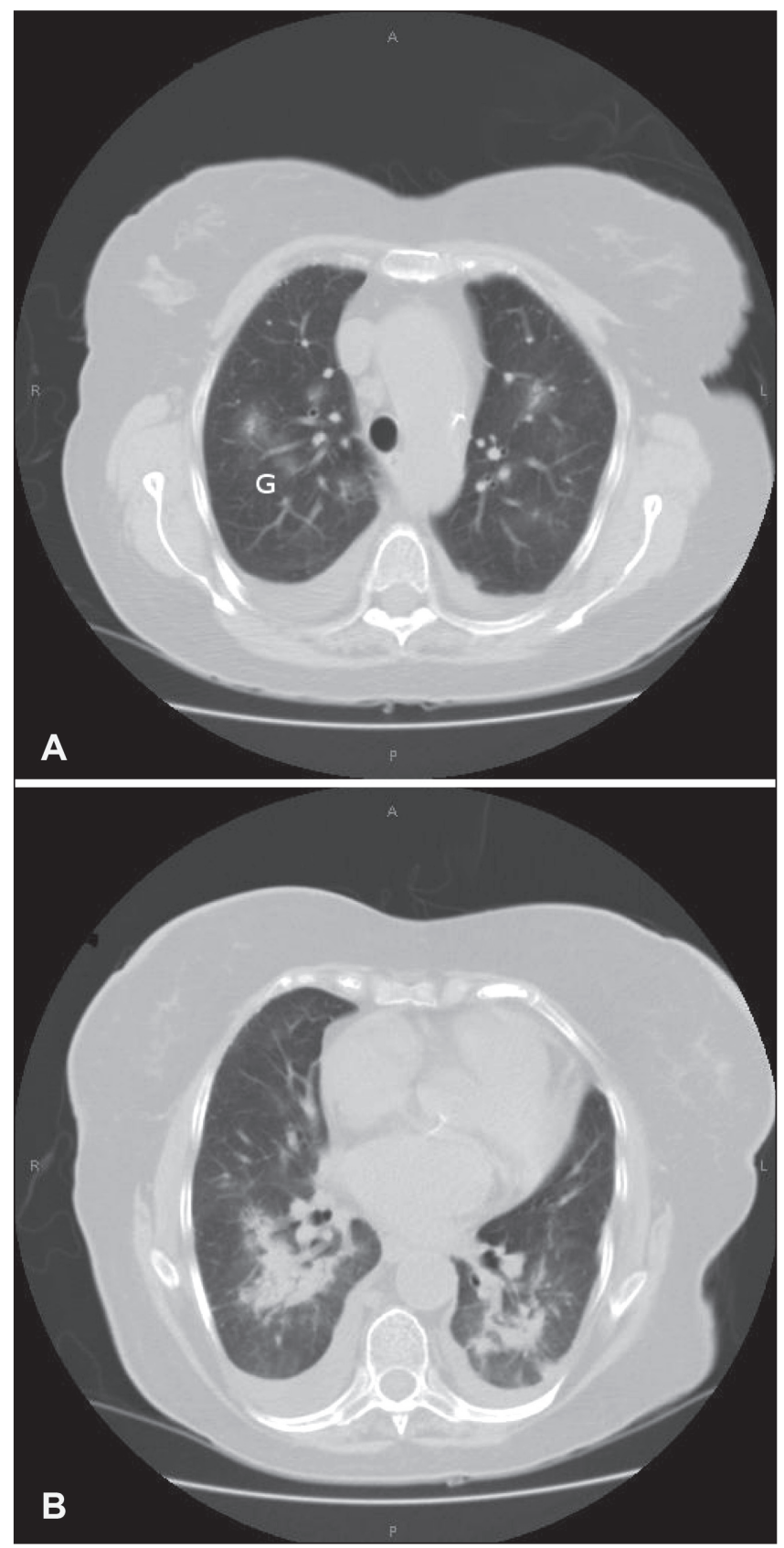

Figure 4) Computed tomography scan of the same patient as seen in Figure 3. A Upper lobe cut shows bilateral patchy infiltrates with some areas of ground glass opacification $(\mathrm{G})$. B A lower lobe computed tomography cut shows bilateral basilar infiltrates and small pleural effusions. Complete resolution occurred after withdrawal of amiodarone and institution of corticosteroids

A more unusual radiographic appearance of APT is the finding of single or multiple pulmonary nodules, or mass-like opacities (31). They are most often seen in the upper lobes, frequently peripheral in location, and may abut the pleura $(10,31,32)$. It has been postulated that these nodules are due to localized accumulation of the drug in an area of previous inflammation $(10,31)$. They are usually high in attenuation because of the presence of iodine-rich amiodarone in type II pneumocytes within the lesions $(31,32)$. It is important to
TABLE 1

High-resolution computed tomography scan findings in amiodarone pulmonary toxicity (APT)

\begin{tabular}{|c|c|c|}
\hline Scan & Findings & Comments \\
\hline \multirow[t]{5}{*}{ Lung parenchyma } & Ground glass opacities & $\begin{array}{l}\text { Peripheral location; may be } \\
\text { an early finding }\end{array}$ \\
\hline & $\begin{array}{l}\text { Interstitial, alveolar or } \\
\text { mixed infiltrates }\end{array}$ & Usually bilateral \\
\hline & $\begin{array}{l}\text { High attenuation areas in } \\
\text { infiltrates }\end{array}$ & $\begin{array}{l}\text { Due to iodine-rich } \\
\text { amiodarone }\end{array}$ \\
\hline & Lung nodules or 'masses' & $\begin{array}{l}\text { May be single or multiple; } \\
\text { often peripheral in location }\end{array}$ \\
\hline & $\begin{array}{l}\text { Dense bibasal reticular } \\
\text { opacities; traction bron- } \\
\text { chiectasis }\end{array}$ & $\begin{array}{l}\text { Suggests pulmonary } \\
\text { fibrosis. May follow acute } \\
\text { APT or as a de novo } \\
\text { process }\end{array}$ \\
\hline Abdomen & $\begin{array}{l}\text { High attenuation in liver } \\
\text { and spleen }\end{array}$ & $\begin{array}{l}\text { Amiodarone and } \\
\text { metabolites in tissue } \\
\text { macrophages }\end{array}$ \\
\hline \multirow[t]{2}{*}{ Pleura } & Pleural thickening & Common \\
\hline & Pleural effusions & $\begin{array}{l}\text { Less common than pleural } \\
\text { thickening }\end{array}$ \\
\hline
\end{tabular}

know that these nodules/masses have increased uptake on fluorodeoxyglucose positron emission tomography (PET) scanning, falsely suggesting a lung neoplasm (32).

The most dramatic manifestation of APT is that of a rapidly progressing diffuse pneumonitis with acute respiratory failure and a picture typical of the acute respiratory distress syndrome (ARDS). It has been described after contrast infusion for pulmonary angiography and particularly in patients undergoing cardiac or pulmonary surgery, especially pneumonectomy $(10,18)$. Van Meighen et al (33) reported an incidence of ARDS of $11 \%$ after pulmonary surgery in patients treated with amiodarone compared with $1.8 \%$ in those not so treated. ARDS has been reported when amiodarone was used prophylactically preoperatively or when used postoperatively to treat a new arrhythmia $(20,33,34)$. Susceptibility to amiodaroneinduced lung damage may be particularly heightened in those undergoing major cardiothoracic surgery because of the frequent presence of chronic lung disease, and the need for concomitant supplemental $\mathrm{O}_{2}$ and mechanical ventilation in the perioperative period. Ashrafian and Davey (18) have highlighted the possibility that amiodarone is an under-recognized cause of acute respiratory failure in the intensive care unit setting. As may be expected, the fatality rate is high in this form of APT. Autopsy findings in these cases invariably reveal diffuse alveolar damage, hyaline membrane formation, septal thickening and foamy macrophages.

Patients may present a clinical picture typical of individuals with advanced pulmonary fibrosis. This may evolve progressively after a documented episode of acute amiodarone-induced pneumonitis. Amiodarone-induced pulmonary fibrosis develops in $5 \%$ to $7 \%$ of patients following typical amiodarone pneumonitis (10). It may, however, present without an obvious antecedent event. In these cases, it is possible that the pneumonitis phase was subclinical and not recognized. Patients usually have dyspnea, hypoxemia, exertional desaturation and sometimes weight loss. Diffuse crackles are heard on auscultation. Chest x-ray shows diffuse interstitial lung disease. On 
HRCT, there are coarse interstitial, reticular or reticulonodular opacities and traction bronchiectasis. Honeycombing is less common than in idiopathic pulmonary fibrosis. While the temporal relationship to amiodarone administration suggests a causal relationship, it is conceivable that some cases represent coincident idiopathic pulmonary fibrosis.

An unusual manifestation of APT is alveolar hemorrhage with associated hemoptysis (26). This complication should be included in the differential diagnosis of hemoptysis in a patient receiving amiodarone.

Due to its unique properties and tendency to accumulate in various organs, extrapulmonary adverse effects should always be sought in patients presenting with APT. Case reports have been published emphasizing the occurrence of simultaneous multiorgan toxicity in patients on this drug (35). In many cases, the adverse effects are dose dependent and subside with a decrease in dose or discontinuation of the medication. Table 2 summarizes some of the extrapulmonary effects ascribed to amiodarone including, where available from the literature, incidence estimates.

\section{DIAGNOSIS}

APT should be suspected in any patient taking amiodarone who has new or worsening symptoms and/or new infiltrates on chest x-ray. Susceptible patients may also be at risk for pulmonary edema, pneumonia, pulmonary embolism or other acute events, which may make the diagnosis difficult. In the appropriate clinical setting, the findings described above on chest $\mathrm{x}$-ray and computed tomography scanning may be sufficient to support the diagnosis and to initiate treatment. Additional evidence when necessary can be obtained by ancillary tests.

Pulmonary function testing usually reveals a restrictive or mixed obstructive/restrictive pattern. The diffusing capacity of the lungs is usually reduced. In the absence of a decline of at least $15 \%$ to $20 \%$ in the $\mathrm{DL}_{\mathrm{CO}}$, significant amiodarone toxicity appears to be unlikely (36). However, an isolated fall in $\mathrm{DL}_{\mathrm{CO}}$ in the absence of clinical evidence of disease is nonspecific and not diagnostic of APT (36).

Fibre optic bronchoscopy with BAL and transbronchial biopsy can be extremely useful, especially in ruling out other causes of diffuse lung disease. BAL may reveal evidence of an inflammatory or immune response $(9-11)$. There is frequently an elevation in polymorphonuclear leukocytes and $\mathrm{T}$ suppressor CD8+ cells. The presence of 'foamy' macrophages is consistent with the diagnosis, but these cells can be seen in up to one-half of nontoxic patients receiving amiodarone (11). However, in the absence of foam cells, the diagnosis of APT is considered unlikely $(10,11)$.

In some cases, where the diagnosis is unclear, open lung biopsy may be necessary. However, this should be avoided if possible because of the tendency for APT to worsen after thoracic surgery, and because these patients usually have impaired cardiac and pulmonary function.

\section{THERAPY}

Once the diagnosis of APT is considered likely, the drug should be discontinued. After stopping, amiodarone resolution is likely to be slow and some degree of worsening may occur before improvement is noted. This has been attributed to the long elimination half-life of the drug and the tendency to
TABLE 2

Adverse extrapulmonary effects of amiodarone

\begin{tabular}{|c|c|c|c|}
\hline Site & Effect (reference) & Incidence, \% & Diagnosis \\
\hline \multirow[t]{2}{*}{ Heart } & Bradycardia (4) & $2-4$ & ECG \\
\hline & AV block & & \\
\hline \multirow[t]{2}{*}{ Thyroid } & Hypothyroidism (1) & 6 & Thyroid function \\
\hline & Hyperthyroidism (1) & $0.9-2$ & tests \\
\hline \multirow[t]{2}{*}{ Skin } & Blue-grey discolouration (1) & $4-9$ & Physical examination \\
\hline & Photosensitivity (1) & $25-75$ & \\
\hline \multirow[t]{2}{*}{ Liver } & $\begin{array}{l}\text { Elevated enzymes (14) } \\
\quad(\text { AST or ALT >2 times normal) }\end{array}$ & $15-30$ & Liver enzymes \\
\hline & Hepatitis/cirrhosis (14) & $<3$ & \\
\hline \multirow[t]{3}{*}{ Eye } & $\begin{array}{l}\text { Corneal microdeposits (4) } \\
\text { (visual blurring, photophobia) }\end{array}$ & $>90$ & Eye examination \\
\hline & $\begin{array}{l}\text { Halo vision (especially at } \\
\text { night) (14) }\end{array}$ & $<5$ & Slit lamp examination \\
\hline & Optic neuropathy (1) & $\leq 1$ & \\
\hline GI & Anorexia/nausea (4) & 30 & History \\
\hline \multirow[t]{2}{*}{ CNS } & Tremor/ataxia (14) & $3-30$ & Physical examination \\
\hline & Insomnia & Unknown & History \\
\hline
\end{tabular}

ALT Alanine aminotransferase; AST Aspartate aminotransferase; AV Atrioventricular; CNS Central nervous system; ECG Electrocardiography; GI Gastrointestinal

concentrate in tissues such as the lung. Some authors have noted that the more insidious the onset of the disease, the slower the resolution (11).

Systemic corticosteroids are recommended for the treatment of APT, although controlled trials demonstrating efficacy are lacking. Generally, prednisone is started in doses of $40 \mathrm{mg} /$ day to $60 \mathrm{mg} /$ day orally and tapered slowly. Again, the pharmacodynamics of amiodarone dictates treatment for four to 12 months. Cases of relapse on early steroid withdrawal have been reported (37). Okayasu et al (37) have postulated that patients with excess adipose tissue, as measured by a high body mass index, are more susceptible to recurrences with steroid tapering because of the high concentration of lipophilic amiodarone within their adipocytes.

The prognosis of amiodarone lung disease is generally favourable when diagnosed early. However, more advanced disease may be fatal or result in pulmonary fibrosis. Mortality is highest among those who develop ARDS (19,20).

\section{MONITORING: PREVENTION}

Patients who are to begin amiodarone therapy should be informed about potential adverse effects and told to report any new respiratory symptoms promptly. They should have an initial chest $\mathrm{x}$-ray and pulmonary function test, including a $\mathrm{DL}_{\mathrm{CO}}$. These baseline studies serve as useful reference points should toxicity be questioned. Current guidelines suggest that a yearly chest $\mathrm{x}$-ray be obtained as long as patients remain on amiodarone treatment (13). An immediate chest $\mathrm{x}$-ray and pulmonary function testing should be performed if there is clinical suspicion of pulmonary toxicity (14). Goldschlager et al (14) have recently updated surveillance guidelines for clinicians who treat patients with amiodarone, including recommendations for monitoring for extrapulmonary toxicity. These include thyroid function testing, monitoring liver enzymes and function, as well as protective measures for skin photosensitivity $(1,4,13,14)$. 
Currently there are no proven measures to prevent APT. The only strategy that appears to be efficacious is that of using the smallest dose possible for any particular patient. Experimentally, in an animal model, vitamin $\mathrm{E}$ has been shown to reduce the extent of pulmonary damage after amiodarone administration (38). As yet, no clinical studies are available to demonstrate that this is an effective preventive strategy.

\section{CONCLUSION}

There are now numerous reports in the literature describing pulmonary toxicity associated with amiodarone. Although the incidence of this complication has decreased with the use of lower doses of amiodarone, it remains an important diagnostic consideration given the increased use of this drug. Clinical manifestations of pulmonary toxicity may be subtle, or severe and life-threatening. With prompt diagnosis, most patients respond favourably to the withdrawal of amiodarone and the administration of corticosteroids. A baseline chest $\mathrm{x}$-ray and pulmonary function study should be performed before starting therapy, and all patients taking amiodarone should be followed carefully and monitored appropriately to ensure prompt diagnosis should this toxicity occur.

ACKNOWLEDGEMENTS: The authors thank Ms J Koller for her assistance in the preparation of the manuscript, IMS Health Canada for data on amiodarone use in Canada, Dr R Fraser and Dr Lili Fu for the pathology photographs, and Dr D Langleben and Dr D Small for reviewing the manuscript.

FUNDING: This work was supported by a research grant supplied by Mount Sinai Hospital Center - Montreal.

\section{REFERENCES}

1. Vassallo P, Trohman RG. Prescribing amiodarone. JAMA 2007;298:1312-22.

2. Ernawati DF, Stafford L, Hughes FD. Amiodarone - Induced pulmonary toxicity. BR J Clin Pharmacol 2008;66:82-7.

3. Zimetbaum P. Amiodarone for atrial fibrillation. N Engl J Med 2007;356:935-41.

4. Siddoway L. Amiodarone: Guidelines for use and monitoring. Am Fam Physician 2003;68:2189-96.

5. Primeau R, Agha A, Giorgi C, et al. Long term efficacy and toxicity of amiodarone in the treatment of refractory cardiac arrhythmias. Can J Cardiol 1989:5:98-104.

6. Roy D, Talajic M, Dorian P, et al. Amiodarone to prevent recurrence of atrial fibrillation. Canadian Trial of Atrial Fibrillation Investigators. N Engl J Med 2000;342:913-20.

7. Aasbo JD, Lawrence AT, Krishnan K, et al. Amiodarone prophylaxis reduces major cardiovascular morbidity and length of stay after cardiac surgery: A meta-analysis. Ann Intern Med 2005; 143:327-36.

8. Rotmensch HH, Belhassen B, Swanson BN, et al. Steady-state serum amiodarone concentrations: Relationship with antiarrhythmic efficacy and toxicity. Ann Intern Med 1984;101:462-9.

9. Jessurum GA, Crijns HJG. Amiodarone pulmonary toxicity. BMJ 1997;314:619-20.

10. Camus P, Martin WJ II, Rosenow EC III. Amiodarone pulmonary toxicity. Clin Chest Med 2004;25:65-75.

11. Martin WJ II, Rosenow EC III. Amiodarone pulmonary toxicity: Recognition and pathogenisis (Part 1). Chest 1988;93:1067-75.

12. Martin WJ II, Rosenow EC III. Amiodarone pulmonary toxicity: Recognition and pathogenesis (Part 2). Chest 1988;93:1242-8.

13. Sunderj R, Kanji Z, Gin K. Pulmonary effects of low dose amiodarone: A review of the risks and recommendations for surveillance. Can J Cardiol 2000;16:1435-40.

14. Goldschlager N, Epstein AE, Naccarelli GV et al. A practical guide for clinicians who treat patients with Amiodarone: 2007. Heart Rhythm 2007;4:1250-9.

15. Polkey MI, Wilson PO, Rees PJ. Amiodarone pneumonitis: No safe dose. Respir Med 1995;89:233-5.

16. Ott MC, Khoor A, Leventhal JP, et al. Pulmonary toxicity in patients receiving low-dose Amiodarone. Chest 2006;123:646-51.

17. Yamada Y, Shiga T, Matsuda N, et al. Incidence and predictors of pulmonary toxicity in Japanese patients receiving low-dose amiodarone. Circ J 2007;71:1610-6.

18. Ashrafian H, Davey P. Is Amiodarone an underrecognized cause of acute respiratory failure in the ICU. Chest 2001;120:275-82.

19. Saussine M, Colson P, Auauzen M, et al. Post-operative acute respiratory distress syndrome: A complication of Amiodarone associated with 100 percent oxygen ventilation. Chest 1992;102:980-1.

20. Greenspon AJ, Kidwell GA, Hurley W, et al. Amiodarone-related post-operative adult respiratory distress syndrome. Circulation 1991;84:407-415.
21. Marchlinski FE, Gansler TS, Waxman HL, et al. Amiodarone pulmonary toxicity. Ann Int Med 1982;97:839-45.

22. Malhotra A, Muse VV, Mark EJ. An 82 year old man with dyspnea and pulmonary abnormalities. Case records of the Massachusetts General Hospital. N Engl J Med 2003;348:1574-85.

23. Kennedy JI, Myers JL, Plumb VJ, et al. Amiodarone pulmonary toxicity. Clinical, radiologic and pathologic correlations. Arch Intern Med 1987;147:50-5.

24. Myers JL, Kennedy JI, Plumb VJ. Amiodarone lung: Pathologic findings in clinically toxic patients. Hum Pathol 1987;18:349-54.

25. Morera J, Vidal R, Morell F, et al. Amiodarone and pulmonary fibrosis. Eur J Clin Pharm 1983;24:591-3.

26. Iskandar SB, Abi-saleh B, Keith RL, et al. Amiodarone-induced alveolar hemorrhage. South Med J 2006;99:329-30.

27. Endoh Y, Hanai R, Uto K, et al. Diagnostic usefulness of KL-6 measurements in patients with pulmonary complications after administration of amiodarone. J Cardiol 2000;35:121-7.

28. Kuhlman JE, Teigen C, Ren H, et al. Amiodarone pulmonary toxicity: CT findings in symptomatic patients. Radiology 1990;177:121-5.

29. Oyama N, Oyama N, Yokoshiki H, et al. Detection of amiodaroneinduced pulmonary toxicity in supine and prone positions: High resolution computed tomography study. Circ J 2005;69:466-70.

30. Zhu YY, Botvinick E, Dae M, et al. Gallium lung scintigraphy in amiodarone pulmonary toxicity. Chest 1988;93:1126-31.

31. Jarand J, Lee A, Leigh R. Amiodaroma: An unusual form of amiodarone-induced pulmonary toxicity. CMAJ 2007;176:1411-3.

32. Azzam I, Tov N, Elias N, et al. Amiodarone toxicity presenting as a pulmonary mass and peripheral neuropathy: The continuing diagnostic challenge. Postgrad Med J 2006;82:73-5.

33. Van Mieghem W, Coolen L, Malysse I, et al. Amiodarone and the development of ARDS after lung surgery. Chest 1994;105:1642-5.

34. Handschin AE, Lardinois D, Schneiter D, et al. Acute amiodaroneinduced pulmonary toxicity following lung resection. Respiration 2003; $70: 310-2$.

35. Chuang CL, Chern MS, Chang SC. Amiodarone toxicity in a patient with simultaneous involvement of cornea, thyroid gland, and lung. Am J Med Sci 2000;320:64-8.

36. Gleadhill IC, Wise RA, Shonfeld SA, et al. Serial lung function in patients treated with amiodarone: A prospective study. Am J Med 1989;86:4-10.

37. Okayasu K, Takeda Y, Kojima J, et al. Amiodarone pulmonary toxicity: A patient with three recurrences of pulmonary toxicity and consideration of the probable risk of relapse. Intern Med 2006;45:1303-7.

38. Card JW, Racz WJ, Brien JF, et al. Attenuation of amiodaroneinduced pulmonary fibrosis by vitamin $\mathrm{E}$ is associated with suppression of transforming growth factor-betal gene expression but not prevention of mitochondrial dysfunction. J Pharmacol Exp Ther 2003;304:277-83. 


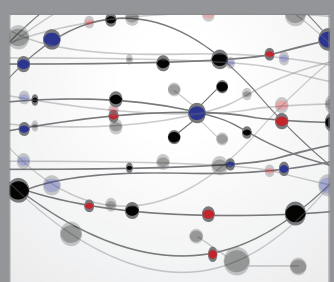

The Scientific World Journal
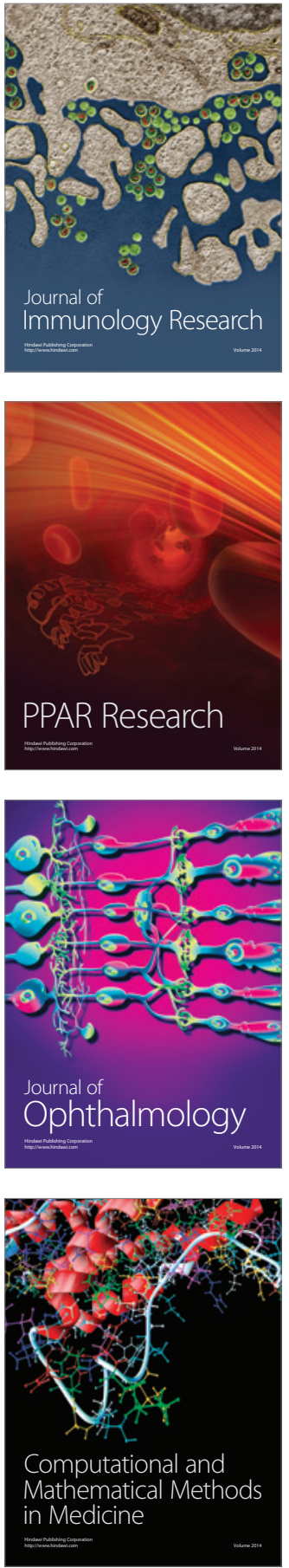

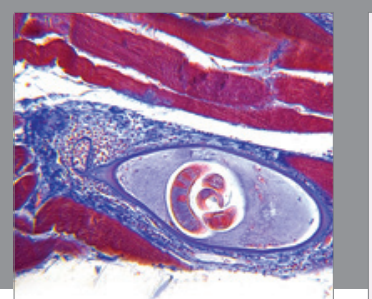

Gastroenterology Research and Practice

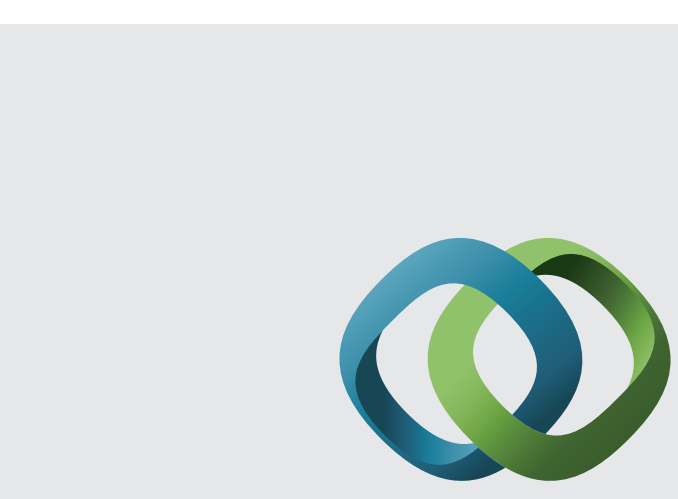

\section{Hindawi}

Submit your manuscripts at

http://www.hindawi.com
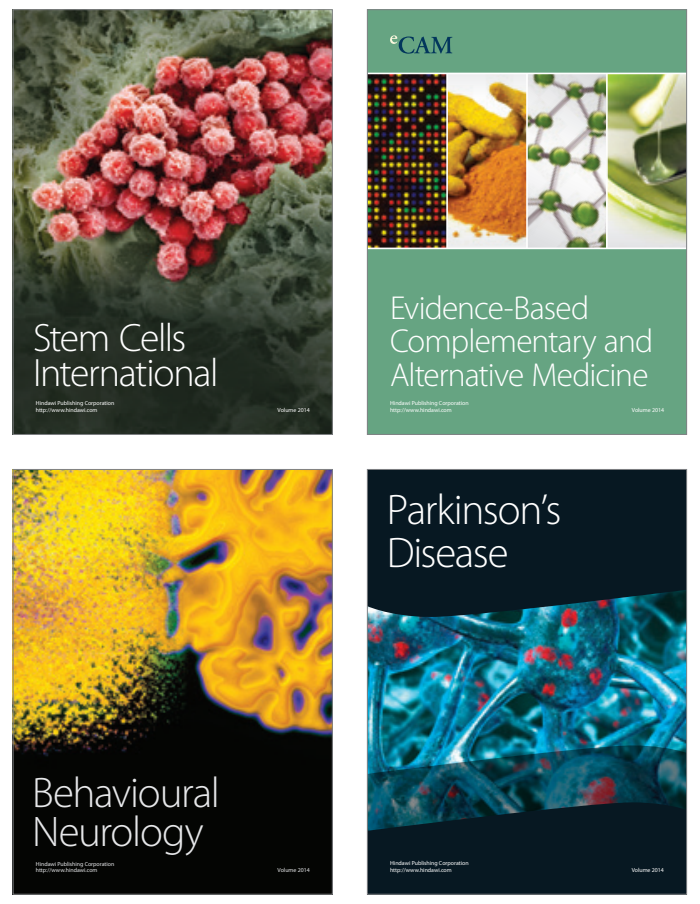
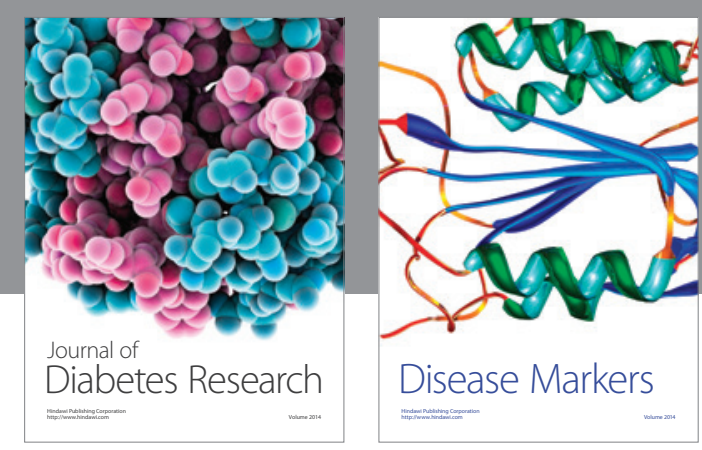

Disease Markers
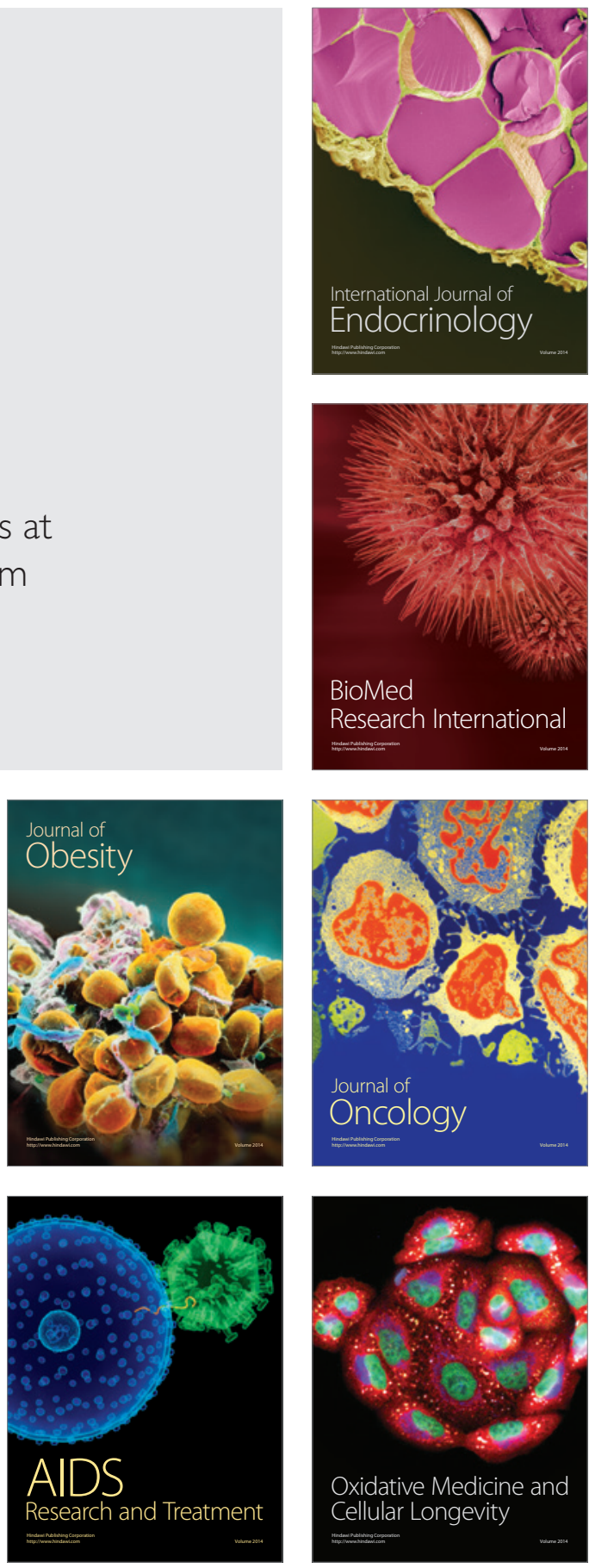